\title{
MIRANDO AL CIELO. \\ El ritual de la plantada y tala del chopo en las fiestas mayores de Vallfogona de Balaguer (Lleida)
}

\author{
Joan TAHULL FORT; Iolanda MONTERO PLAZA; Mercè PLENS GIRAL \\ Universidad de Lleida \\ joantfort@geosoc.udl.cat,ymontero@xtec.cat,mplens@xtec.cat
}

LOOKING AT THE SKY. The ritual of the planted and felling of the poplar in the main festivities of Vallfogona de Balaguer (Lleida)

Resumen: En la investigación se pretende describir, analizar y reflexionar desde una perspectiva social, cultural y antropológica la plantada y tala del chopo en las dos fiestas mayores de Vallfogona de Balaguer (Lleida). Lleva realizándose desde hace más de un siglo. Los habitantes se interesan y participan activamente en el ritual, está integrado en sus vidas y lo consideran algo esencial, específico y único del pueblo y digno de conservar. Se analiza el ritual a partir de las valoraciones, interpretaciones y reflexiones de los vecinos, protagonistas y conocedores de la tradición. Se han realizado 10 entrevistas en profundidad a diferentes personas relacionadas con el evento, desde organizadores, colaboradores y seguidores de diferentes edades. Además los investigadores han participado activamente en las fiestas en diferentes años, realizando observación participante.

Abstract: The research aims to describe, analyze and reflect from a social, cultural and anthropological perspective the planting and felling of the poplar at the two major parties of Vallfogona de Balaguer (Lleida). It has been going on for more than a century. The inhabitants are interested and actively participate in the ritual, it is integrated into their lives and they consider it something essential, specific and unique to the people and worth keeping. The ritual is analyzed based on the assessments, interpretations and reflections of the neighbors, protagonists and connoisseurs of the tradition. There have been 10 in-depth interviews with different people related to the event, from organizers, collaborators and followers of different ages. In addition, researchers have actively participated in the parties in different years, conducting participant observation.

Palabras clave: Ritual. Fiestas populares. Arboles. Juventud. Comunidad. Lleida Community. Ritual. Popular parties Trees. Poplar. Youth 


\section{Introducción}

En esta investigación se pretende describir, analizar y reflexionar sobre la plantada y tala del chopo en las dos fiestas mayores de Vallfogona de Balaguer (provincia de Lleida). Este evento lleva realizándose como mínimo desde hace más de cien años. El árbol queda situado firme colocado en vertical en la plaza de la escuela durante cinco meses, desde la primera o segunda semana de mayo (primera fiesta mayor) hasta la última de septiembre (segunda fiesta mayor), entonces se corta y limpia toda la zona. Durante el resto del año, en el lugar solamente existe como testimonio lo que queda del tronco una vez cortado.

En el estudio se quiere analizar el ritual principalmente a partir de las interpretaciones, valoraciones y reflexiones de los protagonistas, vecinos conocedores a fondo de la tradición que año a año lo repiten, con unas mínimas variaciones y siendo fiel a la tradición. Se han realizado 10 entrevistas en profundidad, a diferentes personas relacionadas con la fiesta de diferente manera, desde los organizadores, aquellos que son responsables continuadores de la tradición, a ancianos que nos han explicado cómo era el evento en su juventud, también a jóvenes del pueblo, explicando cómo lo viven en la actualidad y su interés para proyectarlo hacia el futuro.

Los investigadores han participado en las dos fiestas mayores en diferentes años, pudiendo comprobar de primera mano su evolución y la realización en diferentes circunstancias. Se han obtenido datos mediante la observación participante. Hemos podido participar en todo el proceso, pudiendo observar sin dificultades y recibiendo todas las facilidades. Mientras los organizadores realizaban determinadas acciones, se les preguntaba la motivación y el sentido. Siempre han colaborado y respondido a las cuestiones planteadas. En este estudio pretendemos dar a conocer y visibilizar esta fiesta a la comunidad científica y al público interesado en general. También se han buscado fuentes documentales, aunque existe poca bibliografía al respecto. Esta temática ha sido escasamente estudiada desde las ciencias sociales.

El culto de la plantada del árbol no es extraño en algunos pueblos de Catalunya. Se pueden contar hasta 21 localidades que realizan acciones similares durante sus fiestas mayores (distribuidos en las cuatro provincias catalanas). En cada lugar tiene sus peculiaridades y vitalidad específica. En todo caso, hemos comprobado en general, más allá de estas localidades o sus alrededores, un olvido de estas tradiciones y un desconocimiento de los ciudadanos; también destacar un escaso seguimiento mediático en prensa escrita y/o televisión. Estas fiestas también se realizan en: Andorra, Comunidad Valenciana e Islas Baleares; cada año siguen con la tradición, tienen una participación y seguimiento importante de los vecinos.

Se ha observado todo el proceso de realización, desde la llegada a la ribera del río, horas antes de la tala, para estar y dialogar con los vecinos sobre diversos temas relacionados con la investigación; también se ha comprobado la tensión de los organizadores en determinados momentos, críticos, para fomentar la participación de los vecinos en las diferentes tareas y también en los momentos anteriores a la caída del árbol. Segundos especiales y mágicos, todos contemplan en la misma dirección, pero también peligrosos. Se ha observado el procedimiento de carga y traslado del árbol hasta el pueblo. El esfuerzo y la coordinación de todos los participantes en las diferentes tareas. Se manipula y traslada (unos 3 quilómetros) un chopo de grandes dimensiones (de 20 a 30 metros) de forma rápida y eficaz hasta la plaza de la escuela. Todos saben qué deben hacer, dentro del caos y confusión (principalmente por la gran cantidad de personas y múltiples tareas) se percibe una lógica y un orden interno. Multitud de personas están esperando la llegada del chopo a la plaza de la escuela, hay individuos de diferentes edades. "Els diables" (los diablos) animan y crean una atmósfera mágica, especial, irreal; con mucho ruido, fuego y luz, se tiran todo tipo de petardos. Todo un espectáculo para los sentidos. Una vez colocado el árbol en su lugar, quedará estable durante meses, hasta la llegada del otoño.

Se debe tener en cuenta la relevancia y significación de la plantada y tala del chopo en las dos fiestas mayores para los vecinos de Vallfogona. El hecho social está incrustado en sus vidas, unas semanas antes de las fechas señaladas se empieza a hablar sobre ello, el tiempo que hará, las características del chopo, su altura, la resistencia que opondrá,... También, desde la escuela, cada año, el viernes de la semana anterior se realiza una excursión con todos los alumnos del centro educativo hacia la ribera del río Segre, en el lugar exacto que se sacará el árbol. Durante años, un responsable de la comisión de la plantada y tala del chopo acompañaba a los niños y maestros en la excursión y les explicaba la tradición.

Los investigadores observan una fiesta con mucha vitalidad y participación de vecinos de diferentes edades; con las reflexiones de los jóvenes se intuye que la continuidad y relevo generacional está asegurado. Se interesan y participan activamente en el ritual; está integrado en sus vidas y lo consideran algo esencial, específico, característico y único del pueblo y digno de conservarse. Se sienten íntimamente unidos a ella y no se plantean su desaparición. En las fiestas mayores es el acto más significativo, representativo y multitudinario. 
En esta investigación se pretende dar a conocer, describir e interpretar el ritual de la plantada y tala del árbol y su significación para los habitantes de Vallfogona. Se pretende mostrar la relevancia que tiene para los vecinos y subsanar, aunque mínimamente, la escasez de estudios sobre esta temática.

\section{Fundamentos teóricos}

Estamos incrustados en una sociedad compleja postmoderna. El individualismo está instalado en las comunidades avanzadas. Los grupos humanos necesitan símbolos y rituales para definirse y diferenciarse del resto de grupos. Necesitan periódicamente sentirse y participar de actos comunitarios y recordarse mutuamente que pertenecen, participan y tienen una identidad única y específica (Tahull: 2016).

Plantar un árbol, en este caso un chopo, en la plaza de un pueblo no es un acto desconocido en muchas localidades catalanas. Roviras y Castellet (2017) realizan una breve descripción de los pueblos catalanes que realizan este ritual. La plantada se hace en 21 pueblos catalanes, la mayoría son pueblos pequeños o muy pequeños, de menos de 2000 habitantes, a excepción de Igualada, con una población de 39.316 en el censo de 2017. En cada uno tiene unas características y matices específicos. También se realiza en 4 pueblos de la Comunidad Valenciana, 2 en las Islas Baleares y 2 en Andorra. En todo caso, por las características del evento se requiere la participación e implicación de muchas personas. En estos pueblos tiene mucha significación y reconocimiento pero más allá hay un gran desconocimiento. Cervetó y Roca (2010) describen y analizan la fiesta y el ritual de la plantada en Orrius (provincia de Barcelona, comarca del Maresme). También está la obra citada de Roviras y Castellet (2017), muy general, en la cual se presentan muy sumariamente las 21 plantadas realizadas en Cataluña.

Eliade (2014) explica que en las sociedades avanzadas ha habido un retroceso del ámbito religioso pero todavía se construyen determinados espacios y tiempos sacralizados. En determinados momentos el grupo puede sentir, recuperar y recordar algo originario y primordial, importante y único para ellos, especial, algo que está más allá de la ciencia y la racionalidad. Douglas (1978) establece la distinción entre cultura y naturaleza, entre el orden y el caos. Existe una contradicción y una relación ambivalente y conflictiva entre estos dos espacios opuestos. El ámbito humano es cultural, ha creado símbolos para comprender y dominar el mundo. La naturaleza escapa a las categorías humanas, está impregnada de misterio y elementos azarosos. El hombre siempre ha tenido la voluntad de dominar y controlar la naturaleza. Tiene la voluntad de ordenar aquello descontrolado y caótico, de ponerlo a su servicio y supervisarlo.

Segalen (2005) destaca la relevancia de los rituales en las sociedades avanzadas. Tradicionalmente se relacionaban con lo sagrado pero en la actualidad adoptan formas diferentes, se han adaptado e instalado a los tiempos actuales. Han mutado para determinar una identidad y un sentido de pertenencia a la comunidad. Estos rituales alejan a los individuos de las inercias individualistas, disgregadoras y anómicas. Para Durkheim (1982: 585. En Segalen, 2005: 21) los cultos periódicos, repetidos todos los años con características parecidas, expresan la vida social y cultural de una comunidad en profundidad y producen estados mentales colectivos concretos compartidos por todos:

"Lo esencial es que los individuos estén reunidos, que se experimenten en un común de sentimientos y que estos encuentren expresión en actos comunes (...) Así que todo nos lleva a la misma idea: que los ritos son fundamentalmente medios a través de los cuales se reafirma periódicamente el grupo social"

Las comunidades organizan periódicamente eventos para juntarse, compartir, divertirse y estar todos juntos. Sentirse de nuevo parte de un todo, con una identidad y unos orígenes comunes; contra las fuerzas postmodernas disgregadoras y anómicas. Según Delgado (1999), los cultos profanos son una reacción y defensa ante determinadas fuentes de peligro y contaminación de una sociedad desertificada de referentes y modelos compartidos. Los sentimientos de identidad y unidad dan sentido, proporcionan una efervescencia colectiva, comunidad afectiva o communitas. Los conflictos, las contradicciones y las diferencias se diluyen. En determinados momentos y espacios están todos y están en comunidad y harmonía.

Bauman (2005) reflexiona sobre las dificultades para definir el concepto de identidad. No tiene unas ideas fijas e inmutables, con unos referentes claros y bien definidos. Muchas veces no se expresan o con mucha dificultad. Algunos individuos no se cuestionan el rito y no lo verbalizan, simplemente lo viven y sienten algo especial. El ritual es dinámico, en constante cambio con el paso del tiempo y se integran elementos sociales externos. Se requiere un esfuerzo colectivo para actualizar, conservar y proyectarlo al futuro.

En referencia a la tradición y el ritual de la plantación de los árboles en Vallfogona se desconoce su origen y significados. Los entrevistados no saben su significado profundo ni sus inicios. Afirman no habérselo planteado nunca ni tener un interés especial por saberlo. En todo caso hay obras de referencia sobre el 
origen de la plantación de un árbol en algunas comunidades. Frazer (2008: 70) describe como en algunas comunidades creían que los espíritus de los árboles mejoraban las cosechas. En algunas zonas de Europa era tradicional plantar un árbol o una rama en sus campos cultivados para tener una buena cosecha; también dice que los árboles favorecían la fertilidad de las mujeres, tenían más hijos; y protegían a los rebaños y animales. En muchas culturas europeas los árboles representaban la fertilidad y la abundancia de bienes. Frazer (2008: 71) explica que en Inglaterra, en 1862, en muchas aldeas era común plantar un árbol o una rama:

"En víspera de mayo, todas las familias ponen un arbusto verde salpicado de flores amarillas de las que producen abundantemente los campos. En las comarcas de mucha madera hincan árboles muy altos y delgados que dejan erguido casi todo el año".

En un contexto social y cultural diferente y alejado de Vallfogona se realizaban estas prácticas. Se cortaban árboles y se situaban cerca de los campos, para tener más hijos, mejorar la cosecha y proteger a los animales. Frazer sitúa el ritual de la plantación del árbol en mayo, como en la localidad lleidatana, colocado en la primavera y aproximándose el verano, esperando la cosecha. En un entono más próximo, en el mediterráneo, Pla (1992) destaca que las condiciones de vida son duras y difíciles; con unas diferencias climáticas abruptas entre las diferentes estaciones. Los bienes no están asegurados y se requiere todo el esfuerzo de la comunidad, también mediante rituales para asegurar la cosecha.

Se debe tener en cuenta que para construir un relato social tan intenso y profundo se requiere cierto atrevimiento e imaginación sociológica (Mills: 1983). Se han recogido muchos datos, mediante las entrevistas y las observaciones participantes. Hemos tenido muchas dificultades para discriminar y gestionar toda la información. Se ha pretendido construir un relato coherente, ordenado y con sentido. Algunos datos interesantes no han podido ser introducidos en el relato por incapacidad de los autores y/o perder la coherencia del discurso. Además tener en cuenta que un estudio de estas características pretende adentrarse en las motivaciones ocultas de los participantes y orígenes de la comunidad.

\section{Vallfogona de Balaguer en la actualidad. Aproximación a los aspectos sociales y demográficos actuales}

El municipio está en la provincia de Lleida, en la comarca de la Noguera (capital Balaguer); tiene dos núcleos agregados: la Ràpita y l'Hostal Nou-la Codosa. El pueblo está a 4 quilómetros de la capital de la comarca y a 25 de Lleida ciudad. El pueblo está situado en una llanura, llamada la Plana de Lleida. Hacia el oeste, a 3 quilómetros se localiza el río Segre; en su ribera hay gran cantidad de árboles, principalmente chopos. La Plana de Lleida y el entorno de Vallfogona es rural, con grandes extensiones cultivadas. Los sectores productivos principales son la agricultura (principalmente cereales) y la ganadería (vacuno). La agricultura es extensiva y de regadío. En el paisaje se observan principalmente cultivos, con pocos árboles, aunque en la ribera del río hay muchos chopos. Hacia el norte, a unos 15 quilómetros empiezan los Prepirineos, con la sierra del Montroig y el Montsec.

En el año 2017, según datos del Instituto de Estadística de Catalunya (IDESCAT), en el pueblo había 1.867 habitantes, contando Vallfogona y las dos pedanías. Los vecinos se conocen prácticamente todos; las familias han convivido juntas durante generaciones. En los últimos años el pueblo ha aumentado en población, se ha construido vivienda nueva, posibilitando la llegada de personas de los pueblos cercanos y familias llegadas de diferentes países. Por lo que vimos y nos explicaron la convivencia y la integración de los vecinos es correcta y no se observan ni verbalizan conflictos ni tensiones relevantes. En el pueblo hay diferentes espacios de encuentro, en verano principalmente las piscinas; durante el resto del año: bares, tiendas, parques infantiles, escuela... Hay mucha interacción social entre vecinos de diferentes generaciones, comparten vivencias y experiencias comunes. El pueblo está distribuido principalmente a partir de una calle principal, la Calle Major, la cual cruza el pueblo de este a oeste, con algunas calles perpendiculares y paralelas a esta vía. La fiesta mayor del Roser se ha celebrado los días 11, 12 y 13 de mayo de 2018 (el sábado 12 se plantó el chopo) y la fiesta mayor de Sant Miquel, los días 28, 29 y 30 de septiembre de 2018 (el viernes 28 se cortó).

\section{Panorámica histórica}

Esta parte está realizada en su totalidad a partir de las aportaciones de diferentes vecinos de la localidad. Señalar la escasez de estudios históricos sobre el hecho estudiado, situación que implica no tener informaciones históricas contrastadas y construir el relato principalmente con los recuerdos y vivencias de algunos vecinos, aquellos de más años. En la pregunta sobre los orígenes de la fiesta, las respuestas en todos los casos eran similares, coincidían principalmente en desconocerlos. Se realizaban afirmaciones diciendo que en Vallfogona esta acción o similar se hacía desde siempre; cuando se insistía en la cuestión, ¿desde 

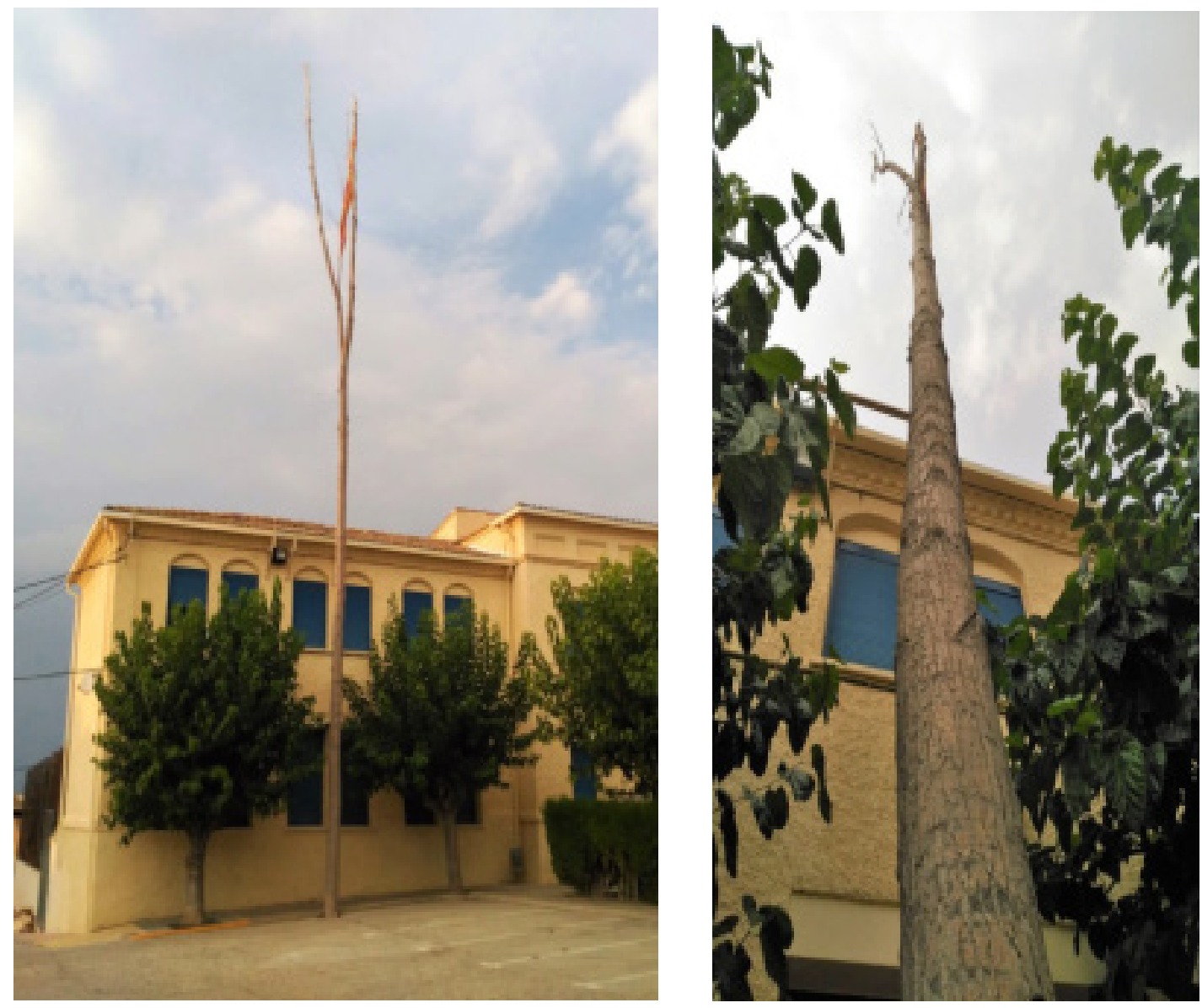

El Chopo una vez "plantado" en la Plaza.

cuándo?, si podían situar los primeros años, todos desconocían las primeras ediciones. Afirmaban que no lo sabían y la mayoría decían que nunca se lo habían cuestionado; ahora que se les preguntaba, tampoco lo consideraban relevante y para ellos no tenía el menor interés. Para ellos es una realidad incrustada en la vida social del pueblo que ha estado desde siempre. Después de insistir, algunos decían que existía desde la Edad Media, sin poder concretar más. Destacar que el pueblo es relativamente reciente, los autores Mateu y otros (2016) sitúan los orígenes entre 1775-1800. Algunos informantes decían que los inicios de la plantada del chopo era más o menos hacia finales de los años 50, sin poder concretar más, lo situaban en sus primeros recuerdos. En todo caso, hay confusión y escasez de datos para situar con claridad los orígenes del ritual. A partir de las diferentes entrevistas realizadas, con los informantes más mayores, parecen situar los orígenes a principios del siglo XX, hacia el año 1910 aproximadamente, sin poder concretar más aunque insisten que posiblemente antes también se realizaba pero no quedan testimonios.

Se les pregunta sobre la motivación e interés para incorporar esta fiesta en el pueblo y lo desconocen. No lo saben. Parece que hay una nebulosa y una indeterminación en referencia sobre el sentido y la motivación del acto. En aquellos años se plantaba un chopo, solamente era un árbol pequeño durante la fiesta mayor. Según parece con los años continuó esta celebración, siempre durante la fiesta mayor, aunque en aquellos años no recuerdan que tuviera una significación especial.

De los años 60 tenemos más informantes e informaciones concretas. Se nos explica que la fiesta del chopo estaba incrustada en la vida social de la comunidad. Era un evento muy significativo de la fiesta mayor, durante las fiestas del Roser, en mayo. Algunos vecinos del pueblo, de diferentes edades, siempre más o menos hombres jóvenes tenían el objetivo de robar un chopo del campo de un agricultor, era pequeño y lo plantaban en la plaza del pueblo; además, estos jóvenes sustraían un carro a un vecino (con el cual transportaban el árbol) y después lo escondían. La cuadrilla sacaba un chopo pequeño de una propiedad privada y lo transportaba con el carro sustraído hacia la plaza. En los días previos a las fiestas, muchos agricultores dormían en los campos y cerca de sus carros para evitar que les cogiesen un árbol y el carro. Cada año había una rivalidad entre la cuadrilla (jóvenes) y los propietarios (adultos) para comprobar quién era más ingenioso y hábil. El agricultor perjudicado, cuando descubría que le faltaba un chopo y, sobretodo el 
carro, se enfadaba contra los jóvenes pero nunca había conflictos graves ni la sangre llegaba al río. Nunca hubo violencia ni agresividad entre las partes, era un hecho social integrado y aceptado por la comunidad.

La plantada era, a partir de los años 50, el acto central de la fiesta mayor, con el baile. Los quintos y diferentes colaboradores participaban en la plantada del chopo, todos eran hombres. Durante el franquismo la sociedad discriminaba a la mujer, éstas tenían un papel secundario, subordinado a los hombres. Los informantes manifiestan que la plantada era un evento fundamentalmente masculino, aunque ellas también estaban y participaban pero siempre en tareas subordinadas y dependientes de ellos. Con la llegada de la democracia en España y hacia los años 80 las mujeres, principalmente las más jóvenes, parejas y novias de los colaboradores, se van incorporando y participando más activamente en la fiesta. Las mujeres van apareciendo y siendo más visibles.

En los años finales de la dictadura, en los 60 y 70, había una sociedad polarizada por dos bandos ideológicos: los próximos al régimen franquista y aquellos cercanos a posturas más catalanistas y progresistas. En Vallfogona, también en otros pueblos de la zona, se realizaban dos fiestas mayores diferentes y separadas. Una en cada extremo del pueblo. Además se realizaban dos plantadas del chopo, cada una tenía su propio público. Será hacia mediados de los años 80 que se unifican las dos, con un baile y una plantada del árbol para todos.

Con la unificación de la fiesta mayor aumenta en magnitud y relevancia. La fiesta es de todos y se pierde el componente de rivalidad entre jóvenes y adultos (se pierde el acto de sustraer el chopo y el carro). Se coordinan las acciones de la plantada con el ayuntamiento y se considera que se debe buscar un chopo de grandes dimensiones en la ribera del Segre; llegando algunos años a tener 25-30 metros de altura. Para realizar las tareas se requiere la colaboración del pueblo, es una labor colectiva i unificadora: (en primavera) cortarlo, trasladarlo y plantarlo; y (en el otoño) cortarlo y limpiar la zona.

\section{El acto central de las fiestas del Roser. Hoy plantamos el chopo}

Con la llegada del buen tiempo, siempre en el mes de mayo, en la primera o segunda semana, en Santa Roser (Rosario) se celebra la fiesta mayor en Vallfogona. Todos los vecinos salen a la calle, para festejar la llegada del buen tiempo y celebrar la fiesta todos juntos. Se organizan diferentes eventos, pero el más significativo y reconocido en el pueblo y alrededores es la plantada del árbol. El lugar de encuentro es en la ribera del río Segre, a unos 3 quilómetros del centro de Vallfogona. En el 2018 se realiza el día 12 de mayo, sábado. Se convoca a los participantes a las 22 horas en una explanada del río. Se coloca un gran foco que ilumina toda la zona, no hay ninguna otra fuente de luz, y se reparten bocadillos y refrescos para todos. Los organizadores quieren que los vecinos vayan al río; nos dicen que en los últimos años bajaban menos y se esperaban en la plaza. Se necesitan personas fuertes y con ganas de estirar el árbol; con esta acción pretenden que participen más en la tala y traslado del tronco.

Los vecinos están hasta las 23:30 horas aproximadamente comiendo, bebiendo y hablando cordialmente. El ambiente es muy agradable y distendido. Las personas son principalmente del pueblo pero también hay de otras poblaciones cercanas. Los participantes parecen sentirse familiarizados y conocedores de la tradición. Algunos han llegado andando desde el pueblo, otros en coche..., después deberán empujar y trasladar el carro con el tronco encima. Realizamos una estimación de los asistentes en la ribera del río, podría haber aproximadamente unas 500 personas de diferentes edades: mayores, adultos y niños, hasta infantes. Realizamos la consulta a los organizadores y dan una cifra parecida.

En los últimos años se sigue el mismo procedimiento en la elección del chopo. Los alumnos de la escuela Salvador Espriu de Vallfogona realizan una excursión de centro (todos los alumnos y maestros) a la ribera del Segre, el viernes de la semana anterior de la fiesta mayor. Oficialmente se dice que son los niños quienes eligen el árbol aunque con la orientación de los maestros. Una vez plantado el árbol estará en la pared principal de la entrada de la escuela durante casi 5 meses.

A las 23:45 horas se corta el árbol de la ribera, siguiendo el modelo tradicional, dando golpes con un hacha. Se establecen las medidas de seguridad, se acordona la zona para evitar peligros. Diferentes personas se van relevando hasta conseguir el objetivo y cortarlo. El público lo ve desde una distancia prudencial; cuando cae, todos están en silencio, ensimismados, y cuando está en el suelo empiezan a chillar y van a verlo y tocarlo, ya en el suelo. Todos están alegres y contentos. Antes de cargarlo se pule el tronco, se cortan las ramas hasta dejarlo solamente como un palo largo; aunque siempre se intenta que en la parte superior del tronco queden ramas con hojas (para favorecer cuando esté plantado la vibración y el movimiento de las hojas).

Una vez pulido el tronco se debe arrastrar hasta el descampado, hasta el carro que lo transportará al pueblo. Se oyen gritos y demandas al público para colaborar en el arrastre. Hombres y mujeres se dirigen hasta el tronco y a partir del coro, "un, dos, TRES", todos a una, lo estiran coordinadamente y con mucho esfuerzo. Desde una mirada externa, de observador, se contempla la complejidad y la plantificación de 
los movimientos de los colaboradores. Todos saben qué deben hacer, aunque hay 12 personas que son los responsables, tienen más experiencia y lideran todo el proceso. Sin ellos sería muy difícil llevarlo a cabo (nunca hacen reuniones previas a las fiestas). Resulta difícil situar el árbol encima del carro, se requiere esfuerzo, coordinación y habilidad. El chopo puede tener entre 20 y 30 metros, depende del año. En el 2018 tenía 24 metros aproximadamente. Una vez colocado en el carro se traslada a toda velocidad al pueblo. Los participantes corriendo lo empujan. A medio camino hay una carretera, el carro la cruza sin pararse, algunos vecinos paran la circulación momentáneamente. En un instante llegan a la plaza de la escuela, son recibidos con una inmensa alegría y gritos.

La plaza está llena de gente, en el ambiente hay mucho júbilo y excitación. Hay una comparsa de música y también "els diables" (los diablos) que realizan un espectáculo para los sentidos de luz, sonido y fuego extraordinario. Se coloca el chopo en el agujero en el cual estará enganchado todo el verano. Entonces los voluntarios van colocando las cuerdas en las diferentes distancias del árbol, para subirlo de forma recta y equilibrada. Hay colaboradores en el suelo, los cuales equilibran el troco para que suba recto (sin desequilibrarse a derecha o izquierda), y otros están en el segundo piso de la escuela, desde allí lo estiran con cuerdas hacia arriba. En el punto más alto del chopo colocan la Senyera (la bandera de Catalunya). Situar el troco vertical correctamente requiere un esfuerzo coordinado y una gran técnica. Los coordinadores, que acostumbran a ser las personas de más edad, van dirigiendo y orientando todos los esfuerzos. Se oyen gritos de "uno, dos, TRES" y poco a poco se va elevando el chopo, con mucho esfuerzo. Una vez situado en vertical, se apuntala, se asegura y así estará varios meses hasta las fiestas de Sant Miquel, en septiembre. Terminado el ritual continúa la fiesta, con orquesta y baile para todos. Los mayores y los infantes van a sus casas, para los jóvenes sigue la diversión.

La fiesta es un espacio y un momento de celebración y encuentro de todos los vecinos. Cuando todos están juntos se superan todos los conflictos y rencillas. Con la finalización de la fiesta mayor llegará el verano y será el tiempo de la recolección y la siega. Los agricultores siempre tienen la esperanza que será un buen año, con una cosecha abundante y sin desgracias de última hora: lluvias torrenciales, granizadas...

\section{Ya ha pasado el verano, lo tiramos}

En los entornos rurales el verano es tiempo de recoger las cosechas. En esta estación hay mucha vitalidad en los espacios públicos. Los agricultores no quieren perder el tiempo, siempre están en movimiento haciendo tareas. Desde primera hora de la mañana, muy temprano están circulando por la carretera, caminos y calles. Deben recoger los frutos del trabajo de todo el año. Siempre hay peligros de última hora que arruine la cosecha, inclemencias meteorológicas. Después de la recolección y superadas las semanas más calurosas del verano llega septiembre, con un tiempo más benigno y suave. En la última semana del mes, en Sant Miquel el 29 de septiembre (San Miguel) llega la segunda fiesta mayor de Vallfogona, se organizan múltiples y variados eventos para todas las edades. En el año 2018 se celebra los días 28,29 y 30 de septiembre.

El primer día, el viernes 28 de septiembre, a las 21:00 horas, la calle principal está llena de gente, conversando y disfrutando del momento. El ayuntamiento ha organizado una cena popular de tapas en todos los bares y restaurantes del pueblo. Los vecinos están en cuadrillas, comiendo y bebiendo. A las 23:00 horas hay programado el espectáculo de "els diables" (los diablos), representando las fuerzas ocultas, oscuras y misteriosas; hay mucho fuego, luz, ruido. Se lanzan multitud de petardos que hacen un sonido atronador. Los niños miran el espectáculo maravillados, extasiados y fuera de sí. Los adultos lo han visto muchas veces pero no dejan de asombrarse como si fuese la primera vez.

A las 00:00 horas se tala chopo. La mayoría del pueblo está en la plaza, contemplando los últimos momentos del árbol plantado en vertical. Ha estado en el mismo lugar durante meses, apuntando al cielo. A la hora en punto finaliza la actuación de "els diables" y se hace el silencio. El público se va acercando a la calle de la escuela, cerca del chopo. Los organizadores van apartando el público hacia lugares seguros. Se colocan vallas de protección y los vecinos se sitúan detrás. La plaza y las calles cercanas están llenas de gente, público diverso, de todas las edades: des de bebés hasta ancianos. Todos quieren ver los últimos momentos del chopo plantado y la tala. Un responsable nos dice que los momentos anteriores a la caída son muy tensos y peligros. Siempre puede haber algún descuido que sea fatal, alguien que en el momento menos apropiado cruce las vallas y entre en la zona de peligro. Los organizadores están en tensión controlando los movimientos de todo el público.

La tala se realiza siguiendo el método tradicional. Diferentes voluntarios se van turnando dando golpes con un hacha hasta el final. El proceso no es rápido y se requiere un esfuerzo importante. Nos dicen que cortarlo en septiembre cuesta mucho; ha estado todo el verano al sol y la madera está reseca. En la caída, el árbol emite un ruido fuerte y seco, expulsando gran cantidad de estrías. En los momentos previos y durante la caída el público se queda mirando el árbol, extasiados, todos a la misma dirección en silencio, el mo- 
mento es mágico. Cuando está en el suelo, todos, ancianos, adultos y niños corren hacia el chopo caído, lo tocan, cogen y guardan algún fragmento de madera. Todos lo quieren mirar y tocar. Poco a poco los niños y ancianos van abandonando la plaza y van hacia sus casas. El día siguiente por la mañana toda la zona está limpia y no queda ningún rastro.

Después de la caída del chopo la fiesta continua, sobre todo para los jóvenes, hay baile para todos. Se cantan y bailan canciones de moda. Poco a poco va llegando la gente al pabellón hasta llenarse. Algunos bailan y otros están en la barra hablando y bebiendo. Hasta las próximas fiestas de la primavera del año siguiente no habrá de nuevo la fiesta mayor y se colocará un nuevo chopo. Poco a poco llegará el frío y las nieblas y los vecinos se recogerán en sus casas. Los agricultores ya han recogido sus cosechas y tendrán el invierno para preparar los campos del año siguiente.

\section{Conclusiones}

En la presente investigación se ha descrito, analizado y reflexionado sobre el ritual de la plantación y tala del chopo en Vallfogona de Balaguer. La información se ha obtenido principalmente a partir de la observación participante de los investigadores, los cuales han estado en diferentes años asistiendo y participando en el ritual. También se han obtenido datos relevantes con entrevistas, desde ancianos a jóvenes, también a coordinadores y organizadores del evento.

Eliade (2014) considera que en las sociedades avanzadas el ritual ha mutado, pasando de ser actos fundamentalmente religiosos a profanos. Se ha preguntado a los entrevistados sobre las motivaciones y orígenes de las fiestas y en todos los casos lo desconocían. No sabían su origen, desde cuándo, cómo y porqué surgió. Algunos afirmaban que la fiesta existía desde siempre, cuando se les preguntaba más llegaban a concretar desde la Edad Media o por allá. Otros relacionaban los inicios con sus recuerdos de sus primeras participaciones. Sabemos por una entrevistada que recuerda el ritual a principios del siglo XX, cuando era una niña. En referencia al significado, también lo desconocen y muchos dicen no interesarles en absoluto. Afirman no habérselo preguntado nunca y ahora que se les interroga, tampoco les interesa.

Frazer (2008) describe rituales parecidos de plantar un árbol en entornos rurales en Inglaterra en el siglo XIX. Estos tenían una significación de fertilidad para las mujeres, asegurar una buena cosecha y aumentar la crianza de los animales. Pla (1992), haciendo referencia a entornos mediterráneos, como Catalunya, con una meteorología extrema y mucha variación térmica entre el invierno y el verano. Las condiciones climáticas hacen la vida de los individuos difícil y la recolección de bienes no está asegurada. Siempre se requiere esfuerzo y atención. Por este motivo surgen en las comunidades rurales diferentes rituales para proteger, conservar y aumentar las cosechas.

En todo caso para los vecinos de Vallfogona en la actualidad las motivaciones e intereses son diferentes. El sentido del ritual para ellos es la fiesta, estar todos juntos dos veces al año (en las fiestas mayores), hacer cosas juntos y divertirse. Superar por unos momentos los posibles conflictos y rencillas. En estos momentos todos son uno. Cada año, por las fiestas, principalmente por la plantada del chopo y la tala, los vecinos se encuentran y se sienten que forman parte de un todo más amplio, con una identidad y unos referentes únicos. Este ritual está incrustado en la vida social, cultural y espiritual de los vecinos de Vallfogona. Por este motivo, no necesitan comprender, racionalizar y explicar los orígenes y las motivaciones ocultas; para ellos simplemente es vida, su vida. Estos actos forman parte intrínseca de su ser y lo viven con la máxima intensidad.

Para finalizar, manifestar la escasez de estudios sobre una temática extendida en diferentes localidades de Catalunya, también en Andorra, Islas Baleares y Comunidad Valenciana; también hacer referencia que el conocimiento de estas fiestas más allá de estos pueblos es poco significativa. Animar a futuros investigadores a abordar esta temática y darla a conocer a la comunidad científica y al público en general. Consideramos que el conocimiento de estos rituales tan complejos e incrustados en la vida social y cultural de sus habitantes dan pistas de la configuración del ser humano: la vida social, la solidaridad, la amistad, las preocupaciones, las prioridades, la subsistencia, la felicidad... Las respuestas están más allá de la realidad concreta de Vallfogona y hacen referencia a lo universal, a la humanidad.

\section{Bibliografía}

Bauman, Z. (2005). Identidad. Madrid: Losada.

Delgado, M. (1999). El animal público. Barcelona: Agranama.

Durkheim, E. (1982). Las formas elementales de la vida religiosa. Madrid: Alianza Editorial.

Eliade, M. (2014). Lo sagrado y lo profano. Barcelona: Paidós. 
Cervetó, E. y Roca, M. (2012). El maig. La festa i el ritual de la plantada a Òrrius. En la revista d'Etnologia de Catalunya, no38, 221-225. Recuperado en: https://www.raco.cat/index.php/RevistaEtnologia/ article/view/259435/346658

Douglas, M. (1978). Símbolos naturales. Madrid: Alianza.

Frazer, J. (2008). La rama dorada. Magia y religión. México: Fondo de Cultura económica.

Mateu, J, Plens, M., Rubió y Torrent, R. (2016). Història de Vallfogona de Balaguer. Dels orígens al repoblament. Lleida: Editorial Pagès.

Mills, C. (1983). La imaginación sociológica. México: Fondo de cultura económica.

Rovira, LL. y Castellet, M. (2017). Amunt! Les festes de l'arbre als Països Catalans. La Bisbal d'Empordà: Edicions Sidilla

Segalen, M. (2005). Ritos y ritual contemporáneos. Madrid: Alianza Editorial.

Soler, J. (2001). Cultura popular tradicional. Barcelona: Pòrtic.

Tahull, J. (2016). La compleja transición de los adolescentes hacia la vida adulta. Revista de Antropología Experimental. 16, pp. 27-44. Disponible en: https://revistaselectronicas.ujaen.es/index.php/rae/ article/view/2853 (Recuperado el 10-10-2018). 